\title{
Langmuir
}

pubs.acs.org/Langmuir

(C) 2009 American Chemical Society

\section{Pd-Supported Catalysts: Evolution of Support Porous Texture along Pd Deposition and Alkali-Metal Doping}

\author{
R. Pellegrini, ${ }^{* \dagger}$ G. Leofanti, ${ }^{\dagger}$ G. Agostini, ${ }^{\ddagger}$ E. Groppo,${ }^{\ddagger}$ M. Rivallan,,${ }^{\ddagger}$ and C. Lamberti \\ ${ }^{\dagger}$ Chimet S.p.A - Catalyst Division, Via di Pescaiola 74, I-52041 Viciomaggio (Arezzo), Italy, ${ }^{*}$ Department of \\ Inorganic, Physical and Materials Chemistry, NIS Centre of Excellence and INSTM Reference Center, University \\ of Turin, Via P. Giuria 7, I-10125 Torino, Italy, ${ }^{\S}$ Consultant, Via Firenze 43, 20010 Canegrate (Milano), Italy, and \\ "Ecole Polytechnique Fédérale de Lausanne (EPFL), GGRC-ISIC, Station 6, CH-1015 Lausanne, Switzerland
}

Received January 8, 2009. Revised Manuscript Received February 19, 2009

\begin{abstract}
Adsorption of $\mathrm{N}_{2}$ at $77 \mathrm{~K}$ and scanning electron microscopy have been used to measure the changes in the support morphology, at nano- and microscale level, along the processes involved in the preparation of a supported Pd catalyst: $\mathrm{Pd}$ deposition, doping, and thermal treatments. Among the investigated supports, viz., activated carbons, $\gamma-\mathrm{Al}_{2} \mathrm{O}_{3}$, $\mathrm{SiO}_{2}$, and $\mathrm{SiO}_{2}-\mathrm{Al}_{2} \mathrm{O}_{3}$ (SA), the $\mathrm{SA}$ one was found particularly sensitive to these processes, as a result of its high plasticity and reactivity. Involved processes can be summarized as follows: (i) During the Pd deposition, the support itself is partially dissolved and removed as a result of both the basicity of the precipitating agent and the final washing. (ii) When the undoped sample is thermally treated up to $823 \mathrm{~K}$, only modest phenomena are observed. (iii) Upon doping with potassium carbonate, the support dissolution continues, and the greater the carbonate concentration, the greater the dissolution extent. In this case the dissolved material is not removed, but reprecipitates (partially outside the pores), during the subsequent drying at $393 \mathrm{~K}$. (iv) When doped samples are thermally treated, the reaction between carbonate and support causes the mobilization of the support itself, with sintering phenomena that can reach the total collapse of the porous structure. The starting temperature of the pore collapse decreases with increasing potassium carbonate concentration. The modification of the support influences, directly or indirectly, the surface properties and the availability of Pd particles that can be doped or even covered by materials from support and made more or less accessible or even inaccessible by pore narrowing, widening, or blocking.
\end{abstract}

\section{Introduction}

Precious metal catalysts are widely used in the supported form on porous materials such as activated carbon, $\gamma$-alumina, silica, silica-alumina, organic polymers, and so forth, with a variety of properties (e.g., particle size, surface area, pore volume and size, mechanical strength and resistance to attrition, thermal stability, etc.). The final catalytic properties depend on the combination of the types of metal (i.e., the active phase) ${ }^{1-4}$ and support. ${ }^{2,4-7}$ Particularly, the support can exhibit a direct influence on the catalytic reaction, as its surface is often active toward reactants and reaction products, but an indirect influence also occurs in that the physical-chemical properties of the support influence the metal dispersion, its resistance to sintering, and the accessibility of active sites to reactants. Some of these aspects have been inves-

*Corresponding author. Phone: + 390575-441565. Fax: + 390575-441424. E-mail: riccardo.pellegrini@chimet.com.

(1) Wiersma, A.; van de Sandt, E. J. A. X.; den Hollander, M. A.; van Bekkum, H.; Makkee, M.; Moulijn, J. A. J. Catal. 1998, 177, $29-39$.

(2) Panagiotopoulou, P.; Kondarides, D. I. Catal. Today 2006, 112, 49-52.

(3) Hegedus, L.; Mathe, T.; Tungler, A. Appl. Catal., A 1996, 147, 407-414.

(4) Bernas, A.; Kumar, N.; Mäki-Arvela, P.; Kul'kova, N. V.; Holmbom, B.;

Salmi, T.; Murzin, D. Y. Appl. Catal., A 2003, 245, 257-275.

(5) van de Sandt, E. J. A. X.; Wiersma, A.; Makkee, M.; van Bekkum, H.; Moulijn, J. A. Appl. Catal., A 1998, 173, 161-173.

(6) Pinna, F.; Menegazzo, F.; Signoretto, M.; Canton, P.; Fagherazzi, G.; Pernicone, N. Appl. Catal., A 2001, 219, 195-200.

(7) Cizmeci, M.; Musavi, A.; Tekin, A.; Kayahan, M. J. Am. Oil Chem. Soc. 2006, 83, 1063-1068.

(8) Markus, H.; Plomp, A. J.; Maki-Arvela, P.; Bitter, J. H.; Murzin, D. Y. Catal. Lett. 2007, 113, 141-146.

(9) Venezia, A. M.; La Parola, V.; Pawelec, B.; Fierro, J. L. G. Appl. Catal., A 2004, 264, 43-51.

(10) Ruta, M.; Semagina, N.; Kiwi-Minsker, L. J. Phys. Chem. C 2008, 112, 13635-13641.

(11) Min, K.-I.; Choi, J.-S.; Chung, Y.-M.; Ahn, W.-S.; Ryoo, R.; Lim, P. K. Appl. Catal., A 2008, 337, 97-104. tigated in the literature, such as the effect of the support chemical properties (e.g., acidity or basicity) ${ }^{8-10}$ or porosity. ${ }^{11,12}$

However, it is often neglected that, during the catalyst synthesis, the original bare support may undergo modifications, at the nano- and microscale level, along with the entire catalyst preparation process that involves metal deposition, washing, thermal treatments, addition of additives, and so forth. For example, some carriers such as activated carbons, can release ashes when contacted with impregnating or washing solutions. ${ }^{5}$ Some others, such as oxidic supports, are partially soluble in acidic and basic solutions used for the deposition of the metal, ${ }^{13-16}$ and the dissolved material can be washed out or can reprecipitate inside the pores. Several supports are sensitive to thermal treatments such as silica, ${ }^{17,18}$ alumina, ${ }^{19}$ titania, ${ }^{20}$ zirconia, ${ }^{21}$ and zeolites, ${ }^{22}$ or this sensitivity can be induced by the modifications to the chemistry of the support occurring in the previous preparation steps.

(12) Okhlopkova, L. B.; Lisitsyn, A. S.; Likholobov, V. A.; Gurrath, M.; Boehm, H. P. Appl. Catal., A 2000, 204, 229-240.

(13) Brunelle, J. P. Pure Appl. Chem. 1978, 50, 1211-1229

(14) Bernal, S.; Calvino, J. J.; López-Cartes, C.; Pintado, J. M.; Pérez-Omil, J. A.; Rodríguez-Izquierdo, J. M.; Hayek, K.; Rupprechter, G. Catal. Today 1999, $52,29-43$.

(15) Balint, I.; Miyazaki, A.; Aika, K. Chem. Mater. 2001, 13, 932-938.

(16) Shah, A. M.; Regalbuto, J. R. Langmuir 1994, 10, 500-504.

(17) Bossi, A.; Leofanti, G.; Moretti, E.; Giordano, N. J. Mater. Sci. 1973, 8, 1101-1109.

(18) Guo, S.-L.; Arai, M.; Nishiyama, Y. Appl. Catal. 1990, 65, 31-44.

(19) Arai, H.; Machida, M. Appl. Catal., A 1996, 138, 161-176.

(20) Yu, J. G.; Yu, J. C.; Ho, W. K.; Leung, M. K. P.; Cheng, B.; Zhang, G. K.; Zhao, X. J. Appl. Catal., A 2003, 255, 309-320.

(21) Mercera, P. D. L.; Vanommen, J. G.; Doesburg, E. B. M.; Burggraaf, A. J.; Ross, J. R. H. Appl. Catal. 1990, 57, 127-148.

(22) Liu, S.-B.; Wu, J.-F.; Ma, L.-J.; Tsai, T.-C.; Wang, I. J. Catal. 1991, 132, 432-439. 
In addition, it is a common practice to modify the catalytic properties by means of proper additives called promoters, modifiers, or dopants. ${ }^{23-25}$ For example, some catalytic processes such as the hydrogenation of phenol to cyclohexanone, ${ }^{26-30}$ the selective hydrogenation of acetylene to ethylene, ${ }^{31}$ and the conversion of syn-gas to methanol ${ }^{32-34}$ require alkali and alkaline earth-doped palladium catalysts. Even in this case, a support can undergo modifications through contact with the doping solutions. ${ }^{17,19,35}$ It turns out that the modifications of the support during the catalyst preparation can affect the availability of the metal particles for the catalytic process to take place. In fact, the metal particles may be covered by dissolved support material, or by the shrinkage of the porous system of the support. Furthermore, the metal particles can undergo doping by foreign species other than the added doping salt, but coming from the support.

During our studies on catalyst preparation and doping, we have frequently faced problems of support modification, for example, on activated carbons and oxides, as alumina, silica, and silica-alumina. In all the cases, the investigation of the changes undergone by the support upon different operations allowed us to better understand the behavior of the supported metal. In this paper we report the results of a systematic study on a sodium-neutralized silica-alumina support, particularly sensitive to these processes, showing how palladium deposition, thermal treatments, and doping with potassium salts lead to changes of the support morphology and, thus, of the catalyst properties.

The study has been carried out mainly by adsorption of $\mathrm{N}_{2}$ at $77 \mathrm{~K}$, and scanning electron microscopy (SEM), in order to assess any morphological changes at the nano- and microscale level, respectively. Also transmission electron microscopy (TEM), temperature-programmed desorption coupled with mass spectrometry (TPD-MS), Fourier transform infrared (FTIR) spectroscopy, and CO chemisorption have been used to better understand the phenomena occurring on the support and their influence on the properties of the metal particles. This last aspect will be presented in more detail in two subsequent papers. ${ }^{36,37}$

\section{Experimental Details}

2.1. Materials. Several supports were investigated: $\gamma$-alumina (A), sodium-neutralized silica-alumina (SA) with a $\mathrm{SiO}_{2} / \mathrm{Al}_{2} \mathrm{O}_{3}$ ratio of 5.7 , silica $(\mathrm{S})$, and three types of activated carbons from wood $(\mathrm{CW})$, coconut shells $(\mathrm{CC})$ and peat $(\mathrm{CP})$. All the supports were in powder form with the exception of $\mathrm{CC}$, which was in granules.

(23) Ponec, V. Appl Catal., A 1997, 149, 27-48

(24) Murata, S.; Aika, K.-I. J. Catal. 1992, 136, 110-117.

(25) Pinxt, H. H. C. M.; Kuster, B. F. M.; Marin, G. B. Appl. Catal., A 2000, 191, $45-54$

(26) Neri, G.; Visco, A. M.; Donato, A.; Milone, C.; Malentacchi, M.; Gubitosa, G. Appl. Catal., A 1994, 110, 49-59.

(27) Scirè, S.; Crisafulli, C.; Maggiore, R.; Minicò, S.; Galvagno, S. Appl. Surf. Sci. 1996, 93, 309-316

(28) Scirè, S.; Minicò, S.; Crisafulli, C. Appl. Catal., A 2002, 235, 21-31

(29) Mahata, N.; Raghavan, K. V.; Vishwanathan, V. Appl. Catal., A 1999, 182, 183-187.

(30) Pillai, U. R.; Sahle-Demessie, E. Appl Catal, A 2005, 281, 31-38.

(31) Park, Y. H.; Price, G. L. Ind. Eng. Chem. Res. 1992, 31, 469-474.

(32) Gusovius, A. F.; Watling, T. C.; Prins, R. Appl. Catal., A 1999, 188, 187-199.

(33) Kazi, A. M.; Chen, B.; Goodwin, J. G.; Marcelin, G.; Rodriguez, N.; Baker,

T. K. J. Catal. 1995, 157, 1-13.

(34) Gusovius, A. F.; Prins, R. J. Catal. 2002, 211, 273-277.

(35) Mercera, P. D. L.; Vanommen, J. G.; Doesburg, E. B. M.; Burggraaf, A. J.;

Ross, J. R. H. Appl. Catal. 1991, 71, 363-391.

(36) Agostini, G.; Pellegrini, R.; Leofanti, G.; Bertinetti, L.; Bertarione, S.; Groppo, E.; Zecchina, A.; Lamberti, C. J. Phys. Chem. C, submitted for publication, 2009

(37) Pellegrini, R.; Leofanti, G.; Agostini, G.; Bertinetti, L.; Bertarione, S.; Groppo, E.; Zecchina, A.; Lamberti, C. J. Catal., submitted for publication, 2009.
Pd precursor was deposited on the supports by the following different procedures:

(a) Pd catalysts supported on A and SA were prepared by the deposition-precipitation (D-P) method, ${ }^{38,39}$ using $\mathrm{Na}_{2} \mathrm{PdCl}_{4}$ as the palladium precursor and $\mathrm{Na}_{2} \mathrm{CO}_{3}$ as the basic agent. The supported palladium hydroxide was then water-washed until residual chlorides were removed, and dried at $393 \mathrm{~K}$ overnight. The final $\mathrm{Pd} / \mathrm{A}$ undoped catalyst contained $1.70 \% \mathrm{Pd}$ and traces of $\mathrm{Na}$. The $\mathrm{Pd} / \mathrm{SA}$ undoped catalyst contained $2.05 \% \mathrm{Pd}$ and some impurities arising from SA $(\mathrm{Na} 2.64 \%, \mathrm{~K} 0.04 \%, \mathrm{Ca} 0.05 \%$, $\mathrm{Mg} 0.04 \%, \mathrm{~S}<0.10 \%$ ). All percentages given above are referred to wt \%; the same holds throughout the whole text.

(b) $\mathrm{Pd} / \mathrm{S}$ catalyst was prepared by dry impregnation (DI) of microspheroidal silica with $\mathrm{Pd}\left(\mathrm{NH}_{3}\right)_{4}\left(\mathrm{NO}_{3}\right)_{2}$ solution followed by drying at $393 \mathrm{~K}$ and calcination at 723 $\mathrm{K}^{32}$ The final $\mathrm{Pd} / \mathrm{S}$ catalyst contained $1.93 \% \mathrm{Pd}$ and $\mathrm{Na}<0.05 \%$

(c) $\mathrm{Pd} / \mathrm{CW}$ and $\mathrm{Pd} / \mathrm{CP}$ were prepared by the D-P method as described above, the Pd loading being $5.0 \%$.

(d) $\mathrm{Pd} / \mathrm{CC}$ was prepared by wet impregnation (WI) with an aqueous solution of $\mathrm{Na}_{2} \mathrm{PdCl}_{4}$ and further chemical reduction as described in ref 40 . The supported palladium phase was then water-washed until residual chlorides were removed, and dried at $393 \mathrm{~K}$ overnight. The Pd loading was $0.5 \%$.

In the case of $\mathrm{Pd} /$ oxide systems, the $\mathrm{Pd}$ deposition was followed by $\mathrm{K}$-doping. K-doped $\mathrm{Pd} / \mathrm{A}$ and $\mathrm{Pd} / \mathrm{S}$ catalysts were obtained by DI of corresponding undoped catalysts with an aqueous solution of potassium carbonate, followed by drying in a static oven for $16 \mathrm{~h}$ at $393 \mathrm{~K}$. The potassium concentration on the final doped catalysts was 3\%. The Pd/SA catalyst was doped with $\mathrm{K}$ by the same method using different dopant compounds, i.e., carbonates and chlorides, in order to obtain $3-12 \%$ of potassium concentration in the final catalyst.

A further thermal treatment at $823 \mathrm{~K}$ was performed on all oxide-based catalysts, both undoped and doped, in a static oven for $30 \mathrm{~min}$. $\mathrm{Pd} / \mathrm{SA}$ was also treated at other temperatures in the $473-1073 \mathrm{~K}$ range with the same procedure, and at 673 and $823 \mathrm{~K}$ in flowing $\mathrm{H}_{2}$ in a quartz reactor. Finally, some doped catalysts were submitted to washing in order to remove the soluble fraction. Washing was performed with water at $318 \mathrm{~K}$ inside a sintered disk filter funnel.

For the $2 \% \mathrm{Pd} / \mathrm{SA}$ systems, a proper nomenclature has been adopted to directly identify the approximate chemical composition of the sample. Thus, undoped $2 \% \mathrm{Pd} / \mathrm{SA}$ is labeled as $\mathrm{Pd}_{\text {und }}$. For samples doped with potassium carbonate, we add the name of the dopant cation followed by the atomic ratio $\mathrm{K} / \mathrm{Pd}$. So, for example, PdK4 represents a sample containing 2\% $\mathrm{Pd}$ and potassium from carbonate salt at $\mathrm{K} / \mathrm{Pd}=4$ at/at. If alkali metal dopants are introduced as compounds other than carbonate, such as chloride, the counterion is indicated by the suffix $(\mathrm{Cl})$, for example $\mathrm{PdK}(\mathrm{Cl}) 4$.

2.2. Characterization Techniques. 2.2.1. Adsorption of $\mathrm{N}_{2}$ at $77 \mathrm{~K}$. The surface area, pore volume and pore size distribution of both catalysts and supports were measured by adsorption of nitrogen at $77 \mathrm{~K}$ on samples pretreated at $393 \mathrm{~K}$ under vacuum for $2 \mathrm{~h}$. Measurements were performed on a

(38) Geus, J. W.; van Dillen, A. J. Preparation of supported catalysts by deposition-precipitation. In Handbook of Heterogeneous Catalysis; Ertl, G., Knözinger, H., Weitkamp, J., Eds.; Wiley-VCH: Weinheim, Germany, 1997; Vol. 1, pp 240-257.

(39) Simonov, P. A.; Likholobov, V. A. Physicochemical aspects of preparation of carbon-supported noble metal catalysts. In Catalysis and Electrocatalysis at Nanoparticle Surfaces; Wieckowski, A., Savinova, E. R., Vayenas, C. G., Eds.; Marcel Dekker, Inc.: New York, 2003; pp 409-454.

(40) Menegazzo, F.; Fantinel, T.; Signoretto, M.; Pinna, F. Catal. Commun. 2007, 8, 876-879. 
Micromeritics ASAP 2000 instrument. Once the adsorption isotherm was obtained, the following calculation methods were used: ${ }^{41,42}$

1. Brunauer-Emmett-Teller (BET) equation in the $0.06-$ $0.20 p / p^{0}$ interval for the determination of surface area $\left(A_{\mathrm{s}}\right)$, and of the parameter $c$ that depends on the interaction between the first monolayer of adsorbed $\mathrm{N}_{2}$ and the solid surface;

2. Gurvitsch method, i.e., the measurement of the $\mathrm{N}_{2}$ volume adsorbed at $p / p^{0}=0.973$ by using a conversion factor for volume of liquid $\mathrm{N}_{2}$ into pores $=1.546\left(\mathrm{~mm}^{3}\right.$ liquid $/ \mathrm{cm}^{3} \mathrm{STP}$ vapor), for the determination of the total pore volume $\left(V_{\mathrm{p}}\right)$;

3. Equation $D_{\mathrm{m}} \stackrel{\mathrm{p}}{=} 4\left(\mathrm{~V}_{\mathrm{p}} / A_{\mathrm{s}}\right)$ for the determination of mean pore diameter (assumed as cylindrical) for oxide supports and oxide-based catalysts, and equation $D_{\mathrm{m}}=2\left(\mathrm{~V}_{\mathrm{p}} / A_{\mathrm{s}}\right)$ for activated carbons and corresponding catalysts, assumed to have slit-shaped pores;

4. Barrett-Joyner-Halenda (BJH) method with the Harkins-Jura equation for the calculation of the thickness of the $\mathrm{N}_{2}$ adsorbed layer, used for the determination of pore distribution of oxide and oxide-based catalysts, here also assumed to have cylindrical pores.

All the data were normalized to the weight of Pd catalysts dried at $393 \mathrm{~K}$ in static air, in order to take into account the effect of matter increase due to Pd and dopant addition, and matter loss caused by thermal treatments. ${ }^{43}$ The weight changes caused by thermal treatments were measured at various temperatures $\left(393-1073 \mathrm{~K}\right.$ ) in different atmospheres (air and $\mathrm{H}_{2}$ ), depending on the catalyst. Before each treatment, all the samples were dried at $393 \mathrm{~K}$ in a static oven for $16 \mathrm{~h}$. The treatments in air consist of heating the sample inside a quartz crucible in a static oven up to the treatment temperature at $10 \mathrm{~K} \mathrm{~min}^{-1}$ and keeping it at this temperature for $30 \mathrm{~min}$. The treatments in $\mathrm{H}_{2}$ consist of heating the sample inside a quartz tube up to the treatment temperature at $10 \mathrm{~K} \mathrm{~min}^{-1}$ in $\mathrm{He}$, switching to $\mathrm{H}_{2}$, and keeping the sample at this temperature for $30 \mathrm{~min}$. In both cases, the sample was cooled to room temperature (RT) and weighted.

2.2.2. Scanning Electron Microscopy. SEM observation was carried out by a Philips XL20 instrument at $30 \mathrm{kV}$ of voltage. The dry sample was put on an aluminum stub covered with a double-layer adhesive disk and then sputtered with gold for 120 s. Electron dispersive spectroscopy (EDS) analysis was performed by an annexed EDAX operating at $15 \mathrm{kV}$.

2.2.3. Transmission Electron Microscopy. High-resolution transmission electron micrographs were obtained with a JEOL 3010 -UHR operating at $300 \mathrm{kV}$, equipped with a $2 \mathrm{k} \times 2 \mathrm{k}$ pixels Gatan US1000 CCD camera. Samples were deposited on a copper grid covered with a lacey carbon film.

2.2.4. FTIR Spectroscopy. The FTIR spectra were recorded at $300 \mathrm{~K}$ at $2 \mathrm{~cm}^{-1}$ resolution, using a Bruker IFS 28 spectrometer, equipped with a cryogenic mercury-cadmium-telluride (MCT) detector. Samples were analyzed in the form of selfsupported pellets inside an IR quartz cell allowing in situ thermal treatments and gas dosages.

2.2.5. Temperature Programmed Desorption Coupled with Mass Spectrometry. TPD was monitored by mass spectrometry on samples previously activated in inert $(\mathrm{He})$ atmosphere at $373 \mathrm{~K}$ for $4 \mathrm{~h}$ (in order to remove most of physisorbed water). During the increase of temperature from $\mathrm{RT}$ to $873 \mathrm{~K}$ at a ramp of $5 \mathrm{~K} \mathrm{~min}{ }^{-1}$

(41) Gregg, S. J.; Sing, K. S. W. Adsorption, Surface Area and Porosity, 2nd ed.; Academic Press, Inc.: New York, 1982.

(42) Rouquerol, F.; Rouquerol, J.; Sing, K. Adsorption by Powders \& Porous Solids. Principles, Methodology and Applications; Academic Press: New York, 1999.

(43) As an example, the weight loss for calcination at $823 \mathrm{~K}$ of the $\mathrm{Pd}_{\text {und }}$ sample is $\Delta \mathrm{Wt}=[\mathrm{Wt}(393)-\mathrm{Wt}(823)] / \mathrm{Wt}(823)=0.0515$. This means that, to estimate the original weight of a sample calcined at $823 \mathrm{~K}$, i.e., Wt(873) measured after calcination has to be multiplied by a factor 1.0534 : Wt $(873)_{\text {norm }}$ $=\mathrm{Wt}(873) /[1-\Delta \mathrm{Wt}]$
Table 1. Effect of Preparation (i.e., Palladium Deposition by D-P, DI, and WI, and Subsequent Doping with Potassium) and Thermal Treatments on Surface Area $\left(A_{\mathrm{s}}\right)$, Pore Volume $\left(V_{\mathrm{p}}\right)$ and Mean Pore Size $\left(D_{\mathrm{m}}\right)$ of Catalysts Supported on Different Carriers ${ }^{a}$

\begin{tabular}{|c|c|c|c|c|c|c|c|}
\hline \multirow{2}{*}{ parameter } & \multirow[b]{2}{*}{ support } & as such & \multicolumn{3}{|c|}{ Pd impregnated } & \multicolumn{2}{|c|}{$\mathrm{K}$ doped $(3 \% \mathrm{~K})$} \\
\hline & & $393 \mathrm{~K}$ & method & $393 \mathrm{~K}$ & $823 \mathrm{~K}$ & $393 \mathrm{~K}$ & $823 \mathrm{~K}$ \\
\hline \multirow{6}{*}{$A_{\mathrm{s}}\left(\mathrm{m}^{2} \mathrm{~g}^{-1}\right)$} & A & 177 & D-P & 200 & 186 & 190 & 176 \\
\hline & $\mathrm{S}$ & 320 & DI & $314^{b}$ & 310 & 151 & 69 \\
\hline & SA & 179 & D-P & 141 & 124 & 99 & 76 \\
\hline & $\mathrm{CW}$ & 982 & D-P & 981 & & & \\
\hline & $\mathrm{CC}$ & 1455 & WI & 1459 & & & \\
\hline & $\mathrm{CP}$ & 876 & D-P & 908 & & & \\
\hline \multirow{6}{*}{$V_{\mathrm{p}}\left(\mathrm{mm}^{3} \mathrm{~g}^{-1}\right)$} & $\mathrm{A}$ & 467 & D-P & 437 & 463 & 407 & 416 \\
\hline & $\mathrm{S}$ & 1138 & DI & $1127^{b}$ & 1104 & 1080 & 999 \\
\hline & SA & 719 & D-P & 827 & 716 & 839 & 655 \\
\hline & $\mathrm{CW}$ & 551 & D-P & 521 & & & \\
\hline & $\mathrm{CC}$ & 510 & WI & 500 & & & \\
\hline & $\mathrm{CP}$ & 672 & D-P & 684 & & & \\
\hline \multirow[t]{6}{*}{$D_{\mathrm{m}}(\AA)$} & A & 106 & D-P & 87 & 100 & 86 & 94 \\
\hline & $\mathrm{S}$ & 142 & DI & $144^{b}$ & 143 & 286 & 579 \\
\hline & SA & 160 & D-P & 235 & 231 & 341 & 346 \\
\hline & $\mathrm{CW}$ & 11 & D-P & 11 & & & \\
\hline & $\mathrm{CC}$ & 7 & WI & 7 & & & \\
\hline & $\mathrm{CP}$ & 15 & D-P & 15 & & & \\
\hline
\end{tabular}

${ }^{a}$ All thermal treatments (at 393 or $823 \mathrm{~K}$ ) have been carried out in air. The data have been normalized to the weight of undoped catalyst dried in air at $393 \mathrm{~K} .{ }^{b}$ Treatment temperature $723 \mathrm{~K}$ (see Section 2. Experimental Details).

under inert flow (1.0 vol \% $\mathrm{Ar}$ (as tracer) in He at a constant flow

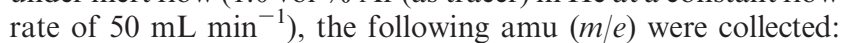
$18\left(\mathrm{H}_{2} \mathrm{O}\right), 28\left(\mathrm{CO} / \mathrm{N}_{2}\right), 32\left(\mathrm{O}_{2}\right), 40(\mathrm{Ar})$, and $44\left(\mathrm{CO}_{2}\right)$.

2.2.6. CO Chemisorption. $\mathrm{CO}$ chemisorption experiments were performed by the dynamic pulse method at $323 \mathrm{~K}$. The catalyst, previously dried at $383 \mathrm{~K}$ overnight, was reduced in situ at $393 \mathrm{~K}$ with the following procedure: (i) the sample was loaded inside a Utube, (ii) it was heated in He up to $393 \mathrm{~K}$ (with a $10 \mathrm{~K} \mathrm{~min}^{-1}$ ramp rate), (iii) $\mathrm{H}_{2}$ was fed for $30 \mathrm{~min}$, and (iv) the sample was finally cooled to $323 \mathrm{~K}$ in $\mathrm{He}$ (with a $10 \mathrm{~K} \mathrm{~min}^{-1}$ ramp rate).

After that, five $\mathrm{CO}$ pulses of known volume were sent to the sample under $\mathrm{He}$ flow, and the adsorbed $\mathrm{CO}$ amount was determined by a TCD detector. In order to determine the available surface $\mathrm{Pd}$ atoms (surface to volume ratio, $S / V_{\mathrm{Chemi}}$ ) a $\mathrm{CO} / \mathrm{Pd}$ average stoichiometry of 1 was assumed. This assumption was verified by a parallel series of measurements performed on three different samples treated at two different temperatures with $\mathrm{H}_{2}-\mathrm{O}_{2}$ static volumetric titration, which gives an $\mathrm{O} / \mathrm{Pd}$ average stoichiometry close to $1 .^{44}$ The two methods/techniques give a $\mathrm{CO} / \mathrm{O}$ ratio in the $0.94-1.13$ range, which is a strong support for the assumption that $\mathrm{CO} / \mathrm{Pd}$ average stoichiometry equals 1. A further confirmation of the assumed stoichiometry comes form the $\mathrm{Pd}_{\text {und }}$ sample reduced in $\mathrm{H}_{2}$ at $393 \mathrm{~K}$. In this case, the fraction of surface atoms derived from the Pd particle size distribution measured by TEM is 0.29 , a value very close to the value of 0.28 obtained from $\mathrm{CO}$ chemisorption assuming a $\mathrm{CO} / \mathrm{Pd}$ average stoichiometry of 1 .

\section{Results and Discussion}

3.1. Support Modifications upon Catalyst Preparation and Treatments. Table 1 reports the results of nitrogen adsorption measurements on catalysts prepared with different methods and on different supports. Measurements have been carried out on undoped as well as on doped samples either dried at $393 \mathrm{~K}$ or calcined at $823 \mathrm{~K}$.

Compared to all the oxidic supports, the activated carbons are more inert toward Pd deposition with different methods (i.e., D-P or WI): only small variations of $A_{\mathrm{s}}$ and $V_{\mathrm{p}}$ are observed

(44) Prelazzi, G.; Cerboni, M.; Leofanti, G. J. Catal. 1999, 181, 73-79. 


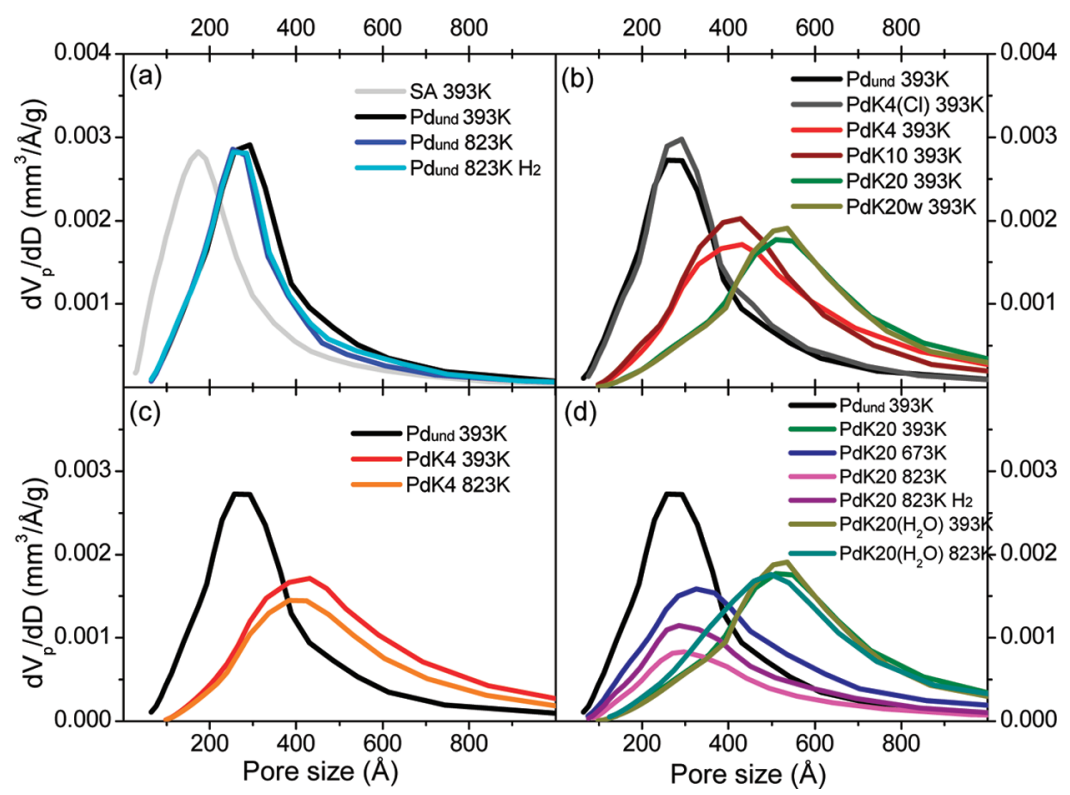

Figure 1. Pore size distribution of undoped, doped, and washed catalysts treated at different temperatures in air or $\mathrm{H}_{2}$ : (a) $\mathrm{SA}$ and $\mathrm{Pd}_{\mathrm{und}}$ samples; (b) effect of doping at $393 \mathrm{~K}$; (c) effect of thermal treatments on PdK4 sample; (d) effect of thermal treatments and washing on PdK20 sample. In panel a, the curves relative to the treatments in air at 473, 573, 673, and $923 \mathrm{~K}$, and in $\mathrm{H}_{2}$ at 393 and $673 \mathrm{~K}$, very similar to those reported, have been omitted for the sake of clarity. Some curves are reported in more than one part in order to make more evident the shifts of pore size distribution.

upon passing from carbon to supported catalyst. Conversely, all the oxidic supports are more sensitive than carbons toward the $\mathrm{Pd}$ addition and exhibit relevant variations upon thermal treatment and/or doping. The extent of the variation depends on the oxide type.

Specifically, as a result of $\mathrm{Pd}$ deposition on $\mathrm{Al}_{2} \mathrm{O}_{3}$ support, $A_{\mathrm{S}}$ increases, and $V_{\mathrm{p}}$ decreases with consequent reduction of $D_{\mathrm{m}}$, confirmed by the pore size distribution (not reported for brevity). Part of the effect is due to the rehydration of alumina. However, a role of etching by basic medium used in the D-P method is highly probable, even if the mechanism is unknown. Upon calcination, the sample shows a loss of $A_{\mathrm{s}}$ with contemporary increase of $D_{\mathrm{m}}$, indicating that the solid has undergone the early effects of sintering process, characterized by growth of larger elementary particles (i.e., $\gamma$-alumina crystals) at the expense of the smaller ones, so that their total area is smaller and the intraparticles spaces (i.e., the pores) are larger. ${ }^{19}$ The doping procedure seems to have a smaller effect than $\mathrm{Pd}$ deposition, bringing about a moderate loss of $A_{\mathrm{s}}$ and $V_{\mathrm{p}}$. Since the carrier was contacted with a basic solution in both cases, (i.e., $\mathrm{Pd}$ deposition and doping), the different behavior can be explained in two different ways: (i) during impregnation the surface irregularities, more sensitive to chemical attack, are quite completely removed, making the second exposure to basic solution during doping less effective, or (ii) the effect is more evident upon palladium deposition because the subsequent washing removes the dissolved material that, conversely, reprecipitates upon drying after doping. Thermal treatment of doped sample has an effect similar to the same treatment on the undoped one: the mechanism is the same and is only slightly influenced by the presence of the dopant, at least up to $823 \mathrm{~K}$.

The $\mathrm{SiO}_{2}$ support is not significantly modified during the impregnation with $\mathrm{Pd}$ because the preparation method (i.e., DI with $\mathrm{Pd}\left(\mathrm{NH}_{3}\right)_{4}\left(\mathrm{NO}_{3}\right)_{2}$ solution) avoids the contact of the support with large volumes of aggressive solutions. Undoubtedly, if the D-P method had been used instead of the DI one, the low resistance of $\mathrm{SiO}_{2}$ toward alkaline solution would have caused heavy modifications of its porous structure. In fact, this occurs upon doping, as this is carried out by filling the pores with $\mathrm{K}_{2} \mathrm{CO}_{3}$ solution followed by drying at $393 \mathrm{~K}$ : a collapse of $A_{\mathrm{s}}$ at almost constant $V_{\mathrm{p}}$ and an enlargement of pores is observed. This can be explained either by the formation of soluble silicates that enable the destruction of the pore walls, or by the solutionprecipitation mechanism, which enables the growth of the silica elementary particles. The effect of thermal treatments strongly depends on the presence of dopant: while the undoped catalyst is almost stable at $823 \mathrm{~K}$, the doped one undergoes a sintering with enlargement of the pores and, consequently, a sharp decrease of $A_{\mathrm{s}}$.

The behavior of SA support is interesting in that it undergoes consistent variations of the morphology at the nano- and microscale level, and this is the reason why we have decided to deeply investigate such support. In fact, it is observed that the use of basic solutions for Pd deposition and doping brings about an enhancement of pore volume and diameter accompanied by a decrease in $A_{\mathrm{s}}$. Moreover, a decrease in $A_{\mathrm{s}}$ and $V_{\mathrm{p}}$ at a constant pore diameter is observed upon thermal treatment at $823 \mathrm{~K}$. This peculiar behavior is discussed in the following sections.

3.2. Processes Occurring during Palladium Deposition on SA. Table 1 indicates that the SA support used for the preparation of the catalysts under investigation has a low resistance toward the solution used during palladium deposition: $A_{\mathrm{s}}$ decreases, while $V_{\mathrm{p}}$ and $D_{\mathrm{m}}$ increase; the last parameter is in agreement with the pore size distribution, which undergoes a general enlargement (Figure 1a). The process that causes such a phenomenon can be explained only with the removal of matter from the inner pores, as will be shown in section 3.4. However, this cannot be thought of as a simple enlargement of pores due to the solubilization of a layer of their walls, because, in that case, we should observe an increase in $V_{\mathrm{p}}$ greater than the increase in $D_{\mathrm{m}}$, and also an increase of $A_{\mathrm{s}}$. For example, on pores with cylindrical shape, the volume is directly proportional to $D_{\mathrm{m}}^{2}$, while the surface is directly proportional to $D_{\mathrm{m}}$. It seems more likely that the solubilization involves the removal of irregularities or diaphragms inside the pores (see, for example, the model of Figure 10a): to a small increase in volume (the volume of 
Table 2. Adsorption of $\mathbf{N}_{2}$ at $77 \mathrm{~K}$ on $\mathbf{P d}$ und Catalyst Submitted to Different Thermal Treatments ${ }^{a}$

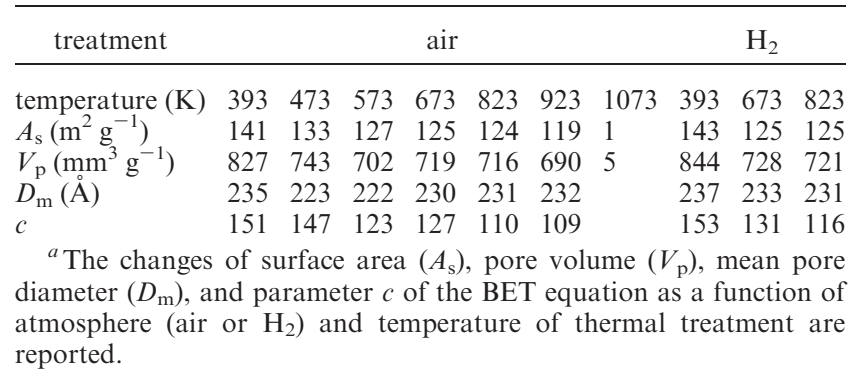

removed matter) corresponds a strong decrease of area (the surface of irregularities or diaphragms) and a real, or apparent, increase in diameter.

Notice that the process hypothesized to occur on SA is totally different from what we have observed on alumina (Table 1), where the support solubility is certainly lower: $A_{\mathrm{s}}$ increases and $V_{\mathrm{p}}$ decreases with consequent decrease of $D_{\mathrm{m}}$.

3.3. Processes Occurring during Calcination and Reduction of $\mathbf{P d} \mathbf{d}_{\text {und }}$ Sample. During calcination, a weight change occurs in the $\mathrm{Pd}_{\text {und }}$ sample, and thus, when different samples are compared, some apparent variations of $A_{\mathrm{s}}$ and $V_{\mathrm{p}}$ are actually due to the "concentration" of the sample caused by loss of water. The problem has been solved by normalizing the data at a given state of the sample, taking into account its composition at the initial stage and after subsequent changes. For this purpose, the sample $\mathrm{Pd}_{\text {und }}$ dried in air at $393 \mathrm{~K}$ has been selected as a reference (see Section 2. Experimental Details).

The effect of calcination temperature on the $\mathrm{Pd}_{\text {und }}$ sample has been deeply investigated by systematically measuring $A_{\mathrm{s}}, V_{\mathrm{p}}$, and $D_{\mathrm{m}}$ in the $393-1073 \mathrm{~K}$ range, as reported in Table 2. Calcination up to $923 \mathrm{~K}$ causes a moderate decrease of $A_{\mathrm{s}}$ and $V_{\mathrm{p}}$, while the pore size $\left(D_{\mathrm{m}}\right)$ remains almost unchanged, as confirmed by the pore size distribution (Figure 1a). The most significant changes occur between 393 and $573 \mathrm{~K}$, suggesting that this is not a phenomenon of classical sintering, which would require higher temperature. On the basis of the results obtained by weight loss measurements and TPD-MS, we can associate the process with the loss of water that is maximum in this range of temperature (Figure 2a) and far more relevant than the release of other substances, such as $\mathrm{CO}_{2}$. Figure $2 \mathrm{~b}$ shows that there is a good correlation between the two processes, i.e., surface area decrease and water loss. Notice that between 673 and $923 \mathrm{~K}$, where most of water has been already released and the loss of weight is low, the variation of $A_{\mathrm{s}}$ is negligible. Moreover, the constancy of $A_{\mathrm{s}}$ confirms that sintering is not operating at lower temperatures, but it requires heating at temperatures higher than $923 \mathrm{~K}$ (Table 2). A further confirmation of this picture comes from the monotonous decrease in the value of the $c$ parameter (from 151 at $393 \mathrm{~K}$ to 123 at $573 \mathrm{~K}$ ) as the temperature of thermal treatment increases, quite similar to what is observed for alumina (from 134 at $393 \mathrm{~K}$ to 97 at $823 \mathrm{~K}$ ), where the only phenomenon that takes place in this range of temperature is the dehydration with loss of hydroxyl groups from the surface. The analogy of the variation of the $c$ parameter for the two types of supports suggests that, in the $\mathrm{Pd}_{\text {und }}$ sample treated at high temperatures, no real chemical reactions between components or decompositions with relevant release of matter are taking place, as these are impossible on alumina. The collapse in $A_{\mathrm{s}}$ observed on a sample treated at $1073 \mathrm{~K}$ is attributable to the presence of residual alkali metal and will be discussed in detail in section 3.5.
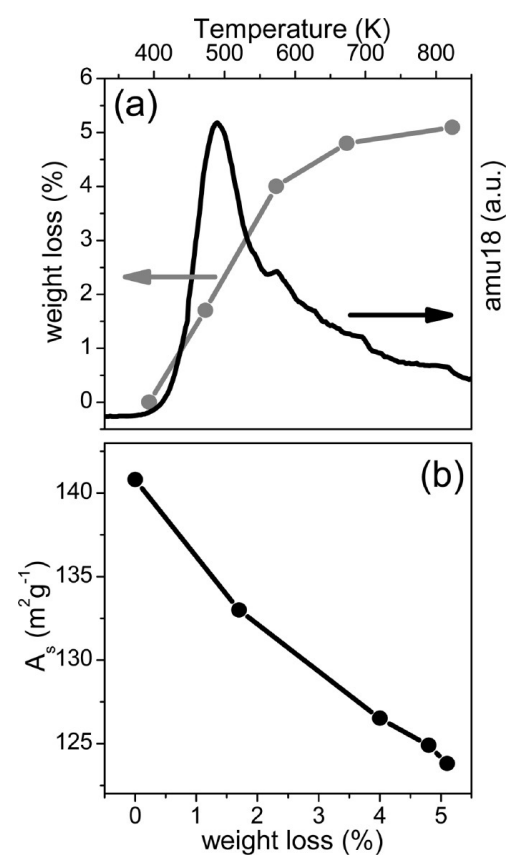

Figure 2. (a) Weight loss at increasing heating temperature in air in a static oven on the $\mathrm{Pd}_{\text {und }}$ sample (gray curve) and $\mathrm{H}_{2} \mathrm{O}$-TPD profile of the same sample (black curve). (b) Surface area decrease on $\mathrm{Pd}_{\text {und }}$ at increasing weight losses (the same as those reported in panel a).

In agreement with this picture, significant differences between treatments in air and $\mathrm{H}_{2}$ are not observed (Table 2 and Figure 1a), pointing out that all the differences induced by the different treatment atmosphere on Pd crystal characteristics and catalytic behavior ${ }^{36,37}$ are not attributable to a different nanoscale morphology.

The observed variations between 393 and $923 \mathrm{~K}$ are too small to define a model based on changes in the local morphology of a solid at the pore level. At most, we can assume that, as a result of dehydration and high temperature treatments, one or both of the following phenomena are apt to occur: (i) occlusion of narrow connections between pores, which leads to a decrease of $V_{\mathrm{p}}$ and $A_{\mathrm{s}}$, but does not change $D_{\mathrm{m}}$, under the hypothesis that the pore blocking is independent of its size; in this case, a significant movement of matter is not involved; (ii) slight shrinking (implying a parallel decrease of $V_{\mathrm{p}}$ and $D_{\mathrm{m}}$ with lower decrease of $A_{\mathrm{s}}$ ) counterbalanced by a smoothing of the pore's inner surface (implying a decrease of $A_{\mathrm{s}}$ at constant $V_{\mathrm{p}}$, with a consequent increase of $D_{\mathrm{m}}$ ); in this case a consistent movement of matter is involved. In Figure 10b a possible model that brings together both mechanisms is proposed.

Finally, notice that the evolution of $A_{\mathrm{s}}, V_{\mathrm{p}}$ and $D_{\mathrm{m}}$ with temperature observed on alumina (Table 1) is quite different: in this case, a mechanism of moderate sintering takes place with growth of elementary larger particles (i.e., $\gamma$-alumina crystals) at the expense of the smaller ones, so that their total area is smaller and the intraparticle spaces (i.e., the pores) are larger.

3.4. Processes Occurring during Doping of $\mathbf{P d}_{\mathrm{und}}$ Sample. As mentioned above, in order to properly analyze the data of doped catalysts, it should be noted that the addition of dopant causes a "dilution" of the catalyst by the added salt, which is certainly nonporous, and thus causes an apparent decrease of $A_{\mathrm{s}}$ and $V_{\mathrm{p}}$ per unit weight of solid. Thus, $\mathrm{N}_{2}$ adsorption data have been normalized to the unit weight of catalyst $\mathrm{Pd}_{\text {und }}$ dried in air at $393 \mathrm{~K}$ (Table 3).

Let us first consider the changes in the pore volume. If all the added matter (i.e., the carbonate) would be located inside the 
Table 3. Adsorption of $\mathrm{N}_{2}$ at $77 \mathrm{~K}$ on Doped Catalysts Dried at $393 \mathrm{~K}$ in $\mathrm{Air}^{a}$

\begin{tabular}{|c|c|c|c|c|c|c|}
\hline \multirow[b]{3}{*}{ treatment } & \multicolumn{6}{|c|}{ Sample } \\
\hline & $\mathrm{Pd}_{\text {und }}$ & $\mathrm{PdK} 4$ & PdK 10 & $\mathrm{PdK} 20$ & $\operatorname{PdK}(\mathrm{Cl}) 4$ & $\mathrm{PdK} 20\left(\mathrm{H}_{2} \mathrm{O}\right)$ \\
\hline & \multicolumn{4}{|c|}{ air $393 \mathrm{~K}$} & air $393 \mathrm{~K}$ & $\operatorname{air} 393 \mathrm{~K}+\mathrm{H}_{2} \mathrm{O}+\operatorname{air} 393 \mathrm{~K}$ \\
\hline$A_{\mathrm{S}}\left(\mathrm{m}^{2} \mathrm{~g}^{-1}\right)$ & 141 & 99 & 104 & 90 & 142 & 90 \\
\hline$V_{\mathrm{p}}\left(\mathrm{mm}^{3} \mathrm{~g}^{-1}\right)$ & 827 & 839 & 851 & 854 & 858 & 833 \\
\hline$D_{\mathrm{m}}(\AA)$ & 235 & 341 & 326 & 381 & 242 & 372 \\
\hline$c$ & 151 & 152 & 163 & 199 & 158 & 180 \\
\hline
\end{tabular}

${ }^{a}$ The changes of surface area $\left(A_{\mathrm{s}}\right)$, pore volume $\left(V_{\mathrm{p}}\right)$, mean pore diameter $\left(D_{\mathrm{m}}\right)$, and parameter $c$ of the BET equation as a function of $\mathrm{K}$ content are reported. The potassium doping salt is $\mathrm{K}_{2} \mathrm{CO}_{3}$ apart from the $\mathrm{PdK}(\mathrm{Cl}) 4$ sample doped with $\mathrm{KCl}$. The $\mathrm{PdK} 20\left(\mathrm{H}_{2} \mathrm{O}\right)$ sample is the PdK20 submitted to washing with water and further drying at $393 \mathrm{~K}$

pores, their volume would suffer a decrease at least equal to the volume of salt. ${ }^{45}$ Conversely, a slight upward trend of $V_{\mathrm{p}}$ is observed. Formally, this would indicate that the carbonate is outside the pores. However, this simple hypothesis presupposes the constancy of $A_{\mathrm{s}}$ and $D_{\mathrm{m}}$ that is not observed, as the former decreases and the latter increases. This means that the expansion of pores is real, as is confirmed by the distribution curves (Figure 1b). ${ }^{46}$

The trend is very similar to that previously observed going from support to catalyst: decrease of $A_{\mathrm{s}}$, slight increase of $V_{\mathrm{p}}$, and increase of $D_{\mathrm{m}}$ and $c$. In that case, it has been assumed that the dissolution concerns the irregularities or diaphragms inside the pores. Here, we can suppose that this process continues during the doping, probably involving adjacent pore walls. A possible objection is that the contact between the catalyst and a basic solution has already occurred during the palladium deposition step (where $\mathrm{Na}_{2} \mathrm{CO}_{3}$ is used) and so, the support irregularities should have been already removed and the effects of the new exposure should be less evident. However, the concentration of dopant $\mathrm{K}_{2} \mathrm{CO}_{3}$ solution, especially on samples with higher $\mathrm{K}$ loading, is much greater than the $\mathrm{Na}_{2} \mathrm{CO}_{3}$ solution used for palladium deposition. Moreover, after $\mathrm{Pd}$ deposition, the catalyst is washed, and so, during the drying at $393 \mathrm{~K}$, the pores are filled only by water. Conversely, doping is not followed by washing, and thus, during the drying step, the pore walls are in contact with a strong basic solution up to 393 $\mathrm{K}$. The conclusion is that, during the catalyst doping, the support is subjected to a much more severe and aggressive environment than during the palladium deposition, and therefore it is reasonable to expect a further chemical attack.

A confirmation that the observed behavior is due to the support dissolution by $\mathrm{K}_{2} \mathrm{CO}_{3}$ has been obtained by two further measurements. The first concerns the catalyst doped with $\mathrm{KCl}$ instead of $\mathrm{K}_{2} \mathrm{CO}_{3}$, i.e., the $\mathrm{PdK}(\mathrm{Cl}) 4$ sample: the solution of $\mathrm{KCl}$ has a neutral $\mathrm{pH}$, so its attacking power toward SA support is rather low. Taking into account the weight correction for the $\mathrm{KCl}$ content, the $\mathrm{PdK}(\mathrm{Cl}) 4$ sample exhibits values of $A_{\mathrm{s}}, V_{\mathrm{p}}, D_{\mathrm{m}}$, and pore size distribution quite similar to the undoped sample: in particular, as shown in Table 3, the $\mathrm{PdK}(\mathrm{Cl}) 4$ sample shows

(45) Considering the simplest model of pores, i.e., cylindrical blind pores, if carbonate is spread on the walls of the pores, their diameter decreases, causing a decrease of volume equal to the volume of salt and proportional to decrease of the diameter. If the carbonate occupies the bottom of the blind pores, the pore diameter does not change, and the volume decrease is still equal to the volume of salt. If the "cap" is over the bottom of the pores, the diameter does not change, and the closer the "cap" is to the pore mouth, the bigger the volume decrease.

(46) It should be noted that, while in most cases $D_{\mathrm{m}}$ and the maximum of pore size distribution have similar values, samples with maximum distribution around 500-550 A exhibit a $D_{\mathrm{m}}$ around $380 \mathrm{~A}$. The reason of this discrepancy is the presence of a very small fraction of micropores, which contribute much more to $A_{\mathrm{s}}$ than to $V_{\mathrm{p}}$. There is neither information available in order to understand the origin of such micropores (probably localized etching), nor indications that their presence nullifies the reported findings, so, in the following, this fact will no longer be discussed. the same $A_{\mathrm{s}}$ and $D_{\mathrm{m}}\left(142 \mathrm{~m}^{2} \mathrm{~g}^{-1}, 242 \AA\right)$ as the undoped $\mathrm{Pd}_{\text {und }}$ sample $\left(141 \mathrm{~m}^{2} \mathrm{~g}^{-1}, 235 \AA\right)$ and is different from the $\mathrm{K}_{2} \mathrm{CO}_{3}$ doped PdK4 sample $\left(99 \mathrm{~m}^{2} \mathrm{~g}^{-1}, 341 \AA\right)$. Therefore, if the doping solution does not cause any support dissolution, the porous structure is not affected.

The second measurement concerns the catalyst $\mathrm{PdK} 20\left(\mathrm{H}_{2} \mathrm{O}\right)$, i.e., the PdK20 sample washed to remove the carbonate or other soluble compounds formed by reaction between carbonate and support (vide infra), and then dried at $393 \mathrm{~K}$. If the changes observed on the catalyst before washing (i.e., PdK20) were due to a precipitation inside the pores of the soluble material from the dopant solution, the washing treatment should restore the initial situation. Indeed, the washing treatment leaves the alterations induced by the doping almost unchanged (Table 3): $\mathrm{PdK} 20$ and $\mathrm{PdK} 20\left(\mathrm{H}_{2} \mathrm{O}\right)$ have the same $A_{\mathrm{s}}$ value $\left(90 \mathrm{~m}^{2} \mathrm{~g}^{-1}\right)$ and $D_{\mathrm{m}}$ values that are close to each other (381 and $372 \AA$, respectively). Consequently, the change at nanoscale morphology of the support upon doping is attributable to deep and irreversible changes in the support structure. ${ }^{47}$

In conclusion, a part of the support dissolves during doping, and then reprecipitates, at least partially, outside the pores during the subsequent drying, with consequent alteration of the whole porous structure. It is likely that the reprecipitated material is made, besides unreacted carbonate, by the product of reaction between carbonate and support (e.g., potassium silicate). ${ }^{17}$ The reaction leads to the decomposition of carbonate with release of $\mathrm{CO}_{2}$ and increase of sample weight lower than expected upon doping, suggesting that, already at the end of drying at $393 \mathrm{~K}$, a fraction of carbonate is decomposed. ${ }^{48}$ The nonreacted carbonate reprecipitates during the drying step, although, probably after the dissolved support because of its higher solubility.

The question is now where the reprecipitated material is located at this stage. Since the pore volume tends to increase slightly with increasing concentration of dopant (Table 3), the amount of material that entered the pores during doping is lower than the material expelled from the pores during drying. Moreover, the material reprecipitated inside the pores is insoluble or slightly soluble in water, as confirmed by the fact that the washing of the PdK20 sample does not cause any increase in $V_{\mathrm{p}}, A_{\mathrm{s}}, D_{\mathrm{m}}$, and pore size distribution. Consequently, we can suppose that the material reprecipitated inside the pores is made by the reaction product of support with carbonate, while the unreacted carbonate is located outside the pores. The phenomenon is confirmed by the SEM observation (Figure 3) showing that the outer surface of the $\mathrm{PdK} 4$ granules is covered by

(47) The unchanged porous texture characteristics do not necessarily imply that the chemistry of the surface remains unchanged: the value of parameter $c$ for the $\mathrm{PdK} 20\left(\mathrm{H}_{2} \mathrm{O}\right)$ sample (180) lies between the values of the unwashed PdK20 sample (199) and the samples with lower K content (152-163).

(48) The decomposed fraction is roughly $80 \%$ in the PdK4 sample and $30 \%$ in the PdK20 one. 

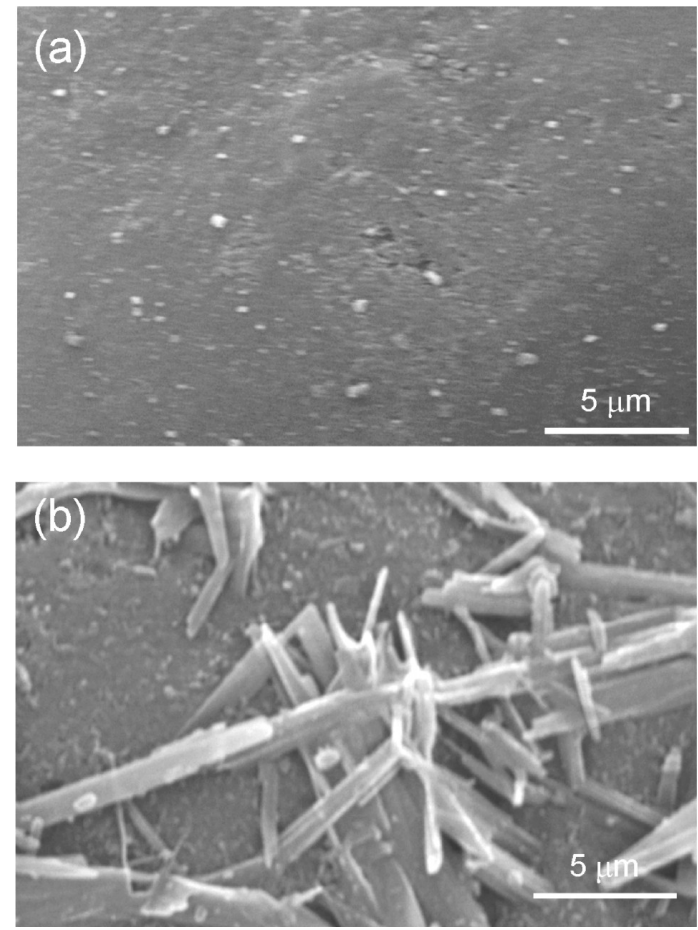

Figure 3. SEM images of the surface of catalyst particles: (a) undoped catalyst $\mathrm{Pd}_{\text {und }}$; (b) doped catalyst PdK4

elongated crystals other than the support that are not observable before doping, constituted mainly by alkaline metal carbonates, as found by EDS analysis.

As far as the chemical nature of the surface is concerned, we observe that the value of $c$ increases with increasing $\mathrm{K} / \mathrm{Pd}$ ratio (Table 3). This is an effect only partially attributable to the contact between $\mathrm{N}_{2}$ and the area covered by carbonate: washing with water brings about a decrease in the value of $c$, but not enough to return to the values of the undoped catalyst. The increase of $c$ as a result of contact with carbonate and subsequent washing is quite similar to that seen by passing from support to the Pd-supported catalyst (Table 1). In that case, the phenomenon has been attributed to a change in the chemistry of the support. In this case, we can invoke further modification of the chemistry of the $\mathrm{Pd}_{\text {und }}$ surface. In Figure 10c, a possible model is reported for the proposed mechanisms occurring during $\mathrm{K}$ doping.

3.5. Processes Occurring during Calcination and Reduction of Doped Samples. We recall that thermal treatments have little effect on undoped catalyst (Table 2 and Figure 1a): a slight decrease of $A_{\mathrm{s}}$ and $V_{\mathrm{p}}$ at constant diameter is observed, which has been interpreted as an occlusion of some narrow channels between contiguous pores, and/or a weak shrinking with smoothing of pores. The effect of thermal treatments on two doped catalysts (PdK4 and PdK20) are reported in Table 4 and shown in Figure 1c,d. Notice that, also in this case, the data have been corrected for both the carbonate content and the loss of $\mathrm{H}_{2} \mathrm{O}$ and $\mathrm{CO}_{2}$. For the sake of clarity, Figure 4 summarizes the evolution of $A_{\mathrm{s}}$ and $V_{\mathrm{p}}$ as a function of temperature for different catalysts.

The effect of thermal treatments up to $1073 \mathrm{~K}$ can be divided into two zones. In the lower temperature range, a slight decrease of $A_{\mathrm{s}}$ and $V_{\mathrm{p}}$ is observed, while $D_{\mathrm{m}}$ (not reported in Figure 4) is constant, as confirmed by the pore size distribution (Figure la,c, d). The range of relative stability of the samples decreases as $\mathrm{K}$ content increases: up to $923 \mathrm{~K}$ for $\mathrm{Pd}_{\text {und }}, 823 \mathrm{~K}$ for $\mathrm{PdK} 4$ and $673 \mathrm{~K}$ for PdK20. At these temperatures, a sudden collapse of $V_{\mathrm{p}}$

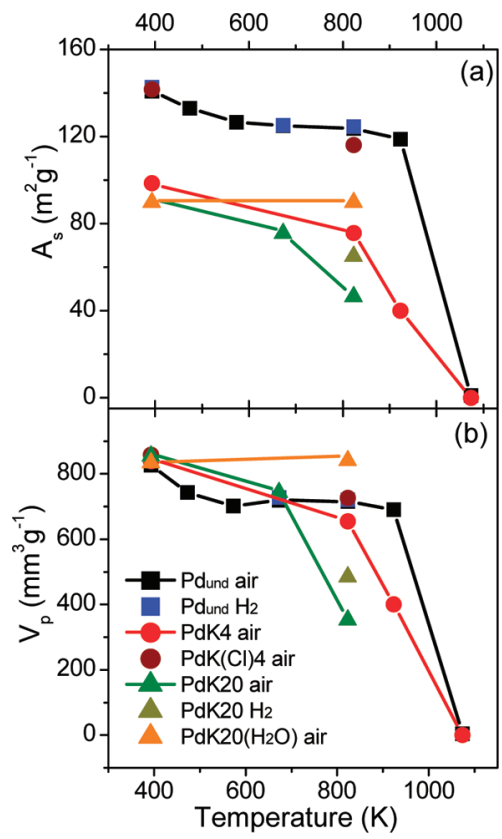

Figure 4. Evolution of $A_{\mathrm{s}}$ (a) and $V_{\mathrm{p}}$ (b) as a function of thermal treatment in air or $\mathrm{H}_{2}$ for $\mathrm{Pd}_{\text {und }}, \mathrm{PdK} 4$, $\mathrm{PdK} 20$, and $\mathrm{PdK} 20\left(\mathrm{H}_{2} \mathrm{O}\right)$. The majority of the data are from Tables $1-4$.

and $A_{\mathrm{s}}$ occurs. The decrease of $V_{\mathrm{p}}$ and $A_{\mathrm{s}}$ is accompanied by a shrinking of pores (see, for example, sample PdK20 at $823 \mathrm{~K}$ in air) and, in much more stressed conditions (sample PdK 4 at 1073 $\mathrm{K}$ in air) leads to the total disappearance of porous structure. The temperature at which the collapse occurs is inversely proportional to the $\mathrm{K} / \mathrm{Pd}$ ratio: $\mathrm{PdK} 20<\mathrm{PdK} 4<\mathrm{Pd}_{\text {und }}$ samples.

The observed changes are clearly due to the presence of carbonate, as confirmed by thermal treatments carried out on the sample PdK20 $\left(\mathrm{H}_{2} \mathrm{O}\right)$, i.e., on the doped sample washed with water. In this case, the characteristics of the sample treated at $823 \mathrm{~K}$ in air are identical to those of the same sample simply dried at $393 \mathrm{~K}$ (see Figure 4): once the carbonate has been removed, the sample is no more affected by the thermal treatments.

The role of carbonate can be explained considering that carbonate becomes reactive with the support at high temperature. In fact, it is well-known that the $\mathrm{K}$ carbonate (or $\mathrm{Na}$ carbonate) is used to dramatically lower the melting temperature of silica (the main component of the SA support) in the preparation of glasses. For example, sodium carbonate starts to react with silica already at $823 \mathrm{~K},{ }^{49}$ giving the following reaction: $\mathrm{Na}_{2} \mathrm{CO}_{3}+\mathrm{SiO}_{2} \rightarrow \mathrm{Na}_{2} \mathrm{SiO}_{3}+\mathrm{CO}_{2}$. The new, chemically modified support becomes mobile already at low temperature because it is well above the Tamman temperature of the pure support. At this point, its porous structure tends to collapse as a result of phenomena such as sintering, which is a process involving the elementary particles of a solid, which progressively assume a form that allows them to adapt to one another in order to gradually occupy the interparticle spaces (pores). ${ }^{50}$ The silicate formed could react with the support not yet modified, thus exalting the effect of the process.

The destabilization of support through reaction with alkali metal carbonate requires (i) the disappearance of potassium

(49) Büchel, K. H.; Moretto, H.-H.; Woditsch, P. Silicate products. In Industrial Inorganic Chemistry; Wiley-VCH: Weinheim, Germany, 2000; pp 325-350.

(50) Randall, M. G. Sintering Theory and Practice; Wiley-Interscience: New York, 1996. 
Table 4. Adsorption of $\mathrm{N}_{2}$ at $77 \mathrm{~K}$ on Doped Catalysts As Such (PdK4 and PdK20) and Water Washed (PdK20( $\left.\mathrm{H}_{2} \mathrm{O}\right)$ ) Submitted to Different Thermal Treatments ${ }^{a}$

\begin{tabular}{|c|c|c|c|c|c|c|c|c|c|}
\hline \multirow[b]{3}{*}{ treatment } & \multicolumn{9}{|c|}{ sample } \\
\hline & \multicolumn{3}{|c|}{$\mathrm{PdK} 4$} & \multicolumn{4}{|c|}{ PdK20 } & \multicolumn{2}{|c|}{$\mathrm{PdK} 20\left(\mathrm{H}_{2} \mathrm{O}\right)$} \\
\hline & air $393 \mathrm{~K}$ & air $823 \mathrm{~K}$ & air $1073 \mathrm{~K}$ & air $393 \mathrm{~K}$ & air $673 \mathrm{~K}$ & air $823 \mathrm{~K}$ & $\mathrm{H}_{2} 823 \mathrm{~K}$ & air $393 \mathrm{~K}$ & air $823 \mathrm{~K}$ \\
\hline$A_{\mathrm{s}}\left(\mathrm{m}^{2} \mathrm{~g}^{-1}\right)$ & 99 & 76 & 0 & 90 & 75 & 46 & 65 & 90 & 90 \\
\hline$V_{\mathrm{p}}\left(\mathrm{mom}^{3} \mathrm{~g}^{-1}\right)$ & 839 & 655 & 0 & 854 & 743 & 352 & 484 & 833 & 840 \\
\hline$D_{\mathrm{m}}(\AA)$ & 341 & 346 & & 381 & 394 & 304 & 298 & 372 & 375 \\
\hline$c$ & 152 & 117 & & 199 & 168 & 159 & 171 & 180 & 249 \\
\hline
\end{tabular}

${ }^{a}$ The changes of surface area $\left(A_{\mathrm{s}}\right)$, pore volume $\left(V_{\mathrm{p}}\right)$, mean pore diameter $\left(D_{\mathrm{m}}\right)$, and parameter $c$ of the BET equation are reported.
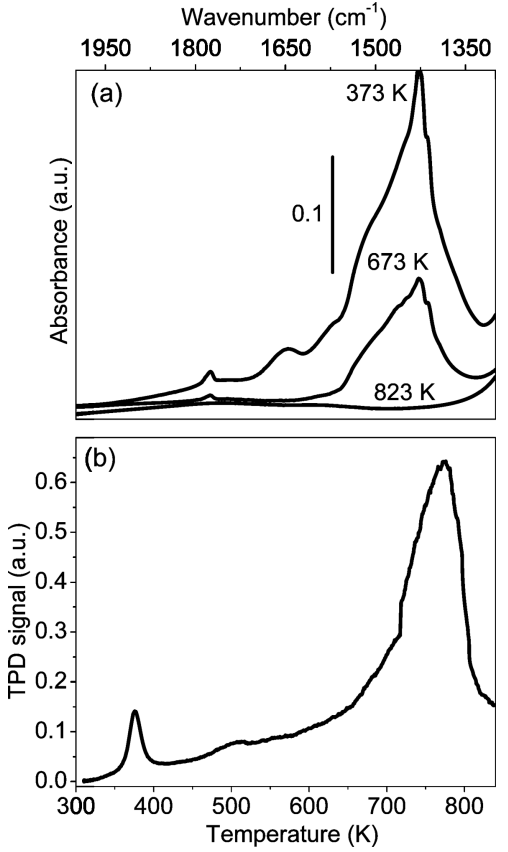

Figure 5. (a) FTIR spectra of PdK4 in the region of carbonates as a function of reduction temperature. (b) $\mathrm{CO}_{2}$-TPD profile of the $\mathrm{PdK} 4$ sample, after previous pretreatment in $\mathrm{He}$ at $373 \mathrm{~K}$ for $4 \mathrm{~h}$
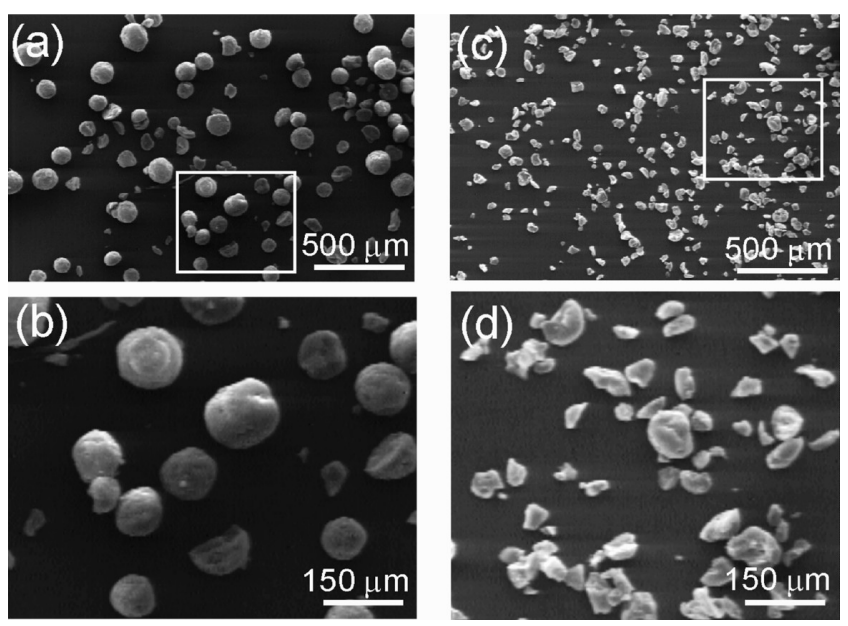

Figure 6. SEM images of the particles of doped PdK20 catalyst. The as-such sample, i.e., treated only at $393 \mathrm{~K}$ (a), and $3 \times$ enlargement (b); sample treated at $823 \mathrm{~K}$ (c) and $3 \times$ enlargement (part d).

carbonate, which is otherwise stable at higher temperature, ${ }^{51}$ and (ii) the release of $\mathrm{CO}_{2}$. In the samples under investigation, the increase of thermal treatment temperature really causes the

(51) Lehman, R. L.; Gentry, J. S.; Glumac, N. G. Thermochim. Acta 1998, 316, $1-9$.

Figure 7. Relationship between Pd dispersion and surface area on $\mathrm{Pd} / \mathrm{SA}$ system submitted to doping with $\mathrm{K}_{2} \mathrm{CO}_{3}$ and to thermal treatments in the 393-823 $\mathrm{K}$ temperature range. The curve qualitatively shows the dispersion versus $A_{\mathrm{s}}$ trend for the samples treated in air. Large and small symbols are associated with treatments in air or $\mathrm{H}_{2}$ atmosphere, respectively. $\mathrm{Pd}_{\text {und }}, \mathrm{PdK} 4, \mathrm{PdK} 10$, and PdK20 data are reported as squares, circles, diamonds, and triangles, respectively; blue, green, and red colors refer to thermal treatments at 393,673 , and $823 \mathrm{~K}$, respectively.

progressive disappearance of carbonate (not yet decomposed after the drying at $373 \mathrm{~K}$ ), as demonstrated by infrared spectroscopy on PdK4 samples treated in the 373-823 K range (see Figure 5a). The sample treated at $373 \mathrm{~K}$ shows a band with a maximum at about $1430 \mathrm{~cm}^{-1}$, typical of the $v_{\text {as }}$ mode of carbonates. ${ }^{52}$ Treatments at higher temperatures cause a decrease of band intensity $(673 \mathrm{~K})$ until the complete disappearance at $823 \mathrm{~K}$. The process is accompanied by the release of $\mathrm{CO}_{2}$, as foreseen by reaction between carbonate and the support, and evidenced by TPD-MS experiment (Figure 5b).

The effect of "alkaline fusion" in the presence of potassium carbonate is confirmed by SEM observations that show a collapse of catalyst particles. In fact, the particles of the as-such PdK20, exhibiting a spherical shape, undergo a reduction of the size and a loss of the spherical shape when treated at $823 \mathrm{~K}$ (Figure 6).

A possible image of the processes described above is shown in the Figure 10d,e where the growth of support particles and the deep interaction between support and carbonate are evidenced: the interacted part, in light green, is a consistent part of the support, and even the entire support. Figure 10d represents the intermediate stage, where a collapse of $A_{\mathrm{s}}$ is observed, but a part of the porous structure has resisted, as observed, for example, on the PdK20 sample treated at $823 \mathrm{~K}$. In Figure 10e, the subsequent total collapse of particles is represented, as occurred, for example, in the PdK4 sample calcined at $1073 \mathrm{~K}$.

(52) Busca, G.; Lorenzelli, V. Mater. Chem. 1982, 7, 89-126. 

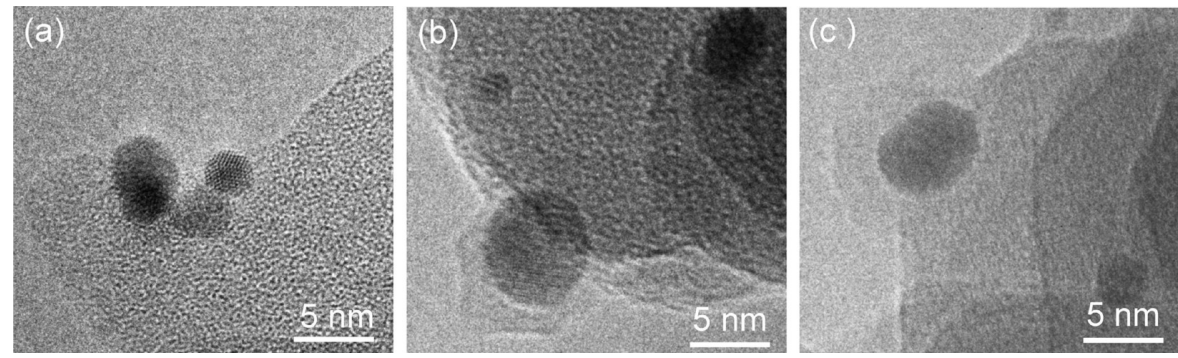

Figure 8. High-resolution TEM images of the particles on Pd/SA catalysts: (a) undoped sample ( $\left.\mathrm{Pd}_{\text {und }}\right)$; (b) sample PdK20 treated at $823 \mathrm{~K}$ in air; (c) the same sample shown in panel $b$ after washing with water.
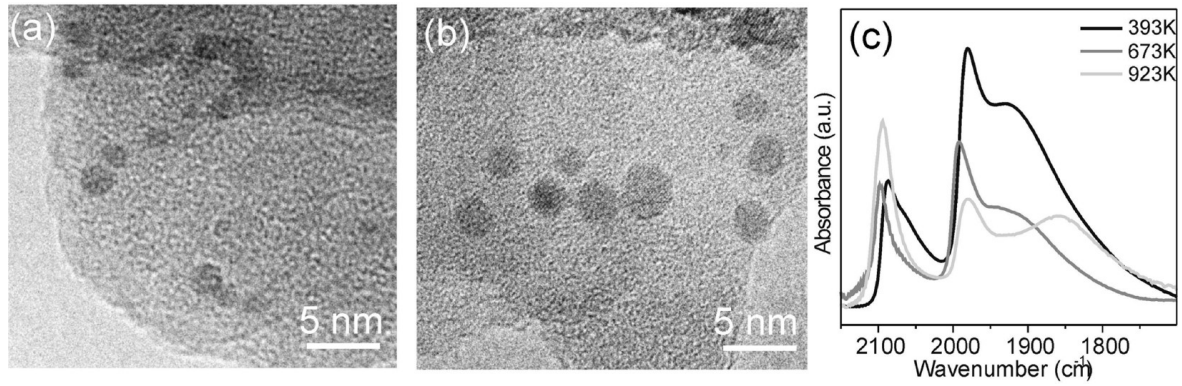

Figure 9. TEM images of the particles of $\mathrm{Pd}_{\text {und }}$ (a) and PdK20 (b) catalysts $\mathrm{H}_{2}$-reduced at $823 \mathrm{~K}$. Part $c$ reports the FTIR spectra of CO $\left(P_{\mathrm{CO}}=50\right.$ Torr) adsorbed on the $\mathrm{Pd}_{\text {und }}$ sample $\mathrm{H}_{2}$-reduced at increasing temperature.

Regarding the atmosphere of the thermal treatment, the $\mathrm{H}_{2}$ seems to have a slight effect on the stability of the PdK20 sample, in the sense that it seems to prevent the collapse of the porous structure. However, the difference between samples treated in air and $\mathrm{H}_{2}$ at $823 \mathrm{~K}$ is moderate, so, being in a phase of great transformation, it can easily be justified by the different experimental setups used in the two cases.

3.6. Effect of Support Changes on Catalyst Properties. The change of the porous structure of the support during Pd deposition, doping, and thermal treatments affects all the characteristics of dispersed Pd crystals. This topic will be deeply discussed in two subsequent papers. ${ }^{36,37}$ Here, some preliminary results are reported to evidence the direct relationship between support modification and Pd properties.

Figure 7 shows the variation of Pd dispersion (as obtained by CO chemisorption) versus $A_{\mathrm{S}}$ (as obtained by adsorption of $\mathrm{N}_{2}$ at $77 \mathrm{~K}$ ) on different samples. Starting with the samples activated in air (larger symbols in Figure 7), it is evident that the decrease of $A_{\mathrm{s}}$ is accompanied by a decrease in Pd dispersion, rather independently of the $\mathrm{K} / \mathrm{Pd}$ atomic ratio and of the temperature necessary to obtain a given loss of surface area. The most relevant phenomenon that links the two processes is the capability of the support to cover progressively palladium crystals, both (i) during reprecipitation caused by drying after dopant addition and (ii) during the support sintering. The process is evidenced by TEM observation, showing on all the doped samples the presence of palladium crystals encapsulated by a phase that, being still present after careful washing with water, has to be ascribed to the modified support. The fraction of palladium crystals covered by the carrier increases with $\mathrm{K} / \mathrm{Pd}$ atomic ratio and calcination temperature, at least from a semiquantitative point of view. Figure 8 shows representative images in the case of $\mathrm{Pd}_{\text {und }}$ and $\mathrm{PdK} 20$ before and after washing. The contribution of other processes, if operating, is surely less effective. Pd sintering is negligible in the operating conditions, as demonstrated by TEM, ${ }^{36,37}$ and the direct covering by carbonate salt can be rejected because the encapsulating phase is insoluble in water, and it tends to increase with temperature while the carbonate decomposes.

The metal encapsulation observed by TEM is quite similar to that observed in the case of strong metal-support interaction (SMSI) effect that is typically associated with reducible supports (i.e., $\left.\mathrm{TiO}_{2}, \mathrm{CeO}_{2}\right){ }^{53,54}$ In that case, the chemisorption capability of the metal particles by probe molecules (i.e., $\mathrm{H}_{2}$ or $\mathrm{CO}$ ) heavily decreases by $\mathrm{H}_{2}$-reduction at high temperature $(\geq 773 \mathrm{~K}){ }^{53}$ due to a particle decoration by the mobilized reduced support. However, care must be done in order to distinguish true SMSIlike phenomena, as originally defined by Tauster et al., ${ }^{53,54}$ from effects similar to SMSI, but having a different origin. ${ }^{55}$ This is the case of the present system, where the $\mathrm{Pd}$ particles coverage is caused by support mobility in absence of $\mathrm{H}_{2}$ : a first $\mathrm{Pd}$ particle coverage occurs because of reprecipitation of the modified support caused by dopant addition, and a second one occurs because of support sintering.

Thermal treatments in $\mathrm{H}_{2}$ (smaller symbols in Figure 7) cause a diminution of dispersion higher than those observed in air, $A_{\mathrm{s}}$ being equal. This means that other processes not directly related to support changes are operating, such as sintering and poisoning, as evidenced by TEM (Figure 9a,b) and IR spectroscopy of adsorbed CO (Figure 9c), respectively. ${ }^{36,37}$

\section{Conclusions}

The changes in the support morphology, at nano- and microscale level, along the processes involved in the preparation of a supported $\mathrm{Pd}$ catalyst have been investigated by adsorption of $\mathrm{N}_{2}$ at $77 \mathrm{~K}$ and SEM. In particular, the effect of $\mathrm{Pd}$ deposition, doping and thermal treatments have been studied. The investigation of $\mathrm{Pd}$ properties and of the catalytic

(53) Tauster, S. J.; Fung, S. C.; Garten, R. L. J. Am. Chem. Soc. 1978, 100, 170 175

(54) Tauster, S. J. Acc. Chem. Res. 1987, 20, 389-394.

(55) Bernal, S. Calvino, J. J.; Cauqui, M. A.; Gatica, J. M.; López Cartes, C.; Pérez Omil, J. A.; Pintado, J. M. Catal. Today 2003, 77, 385-406. 


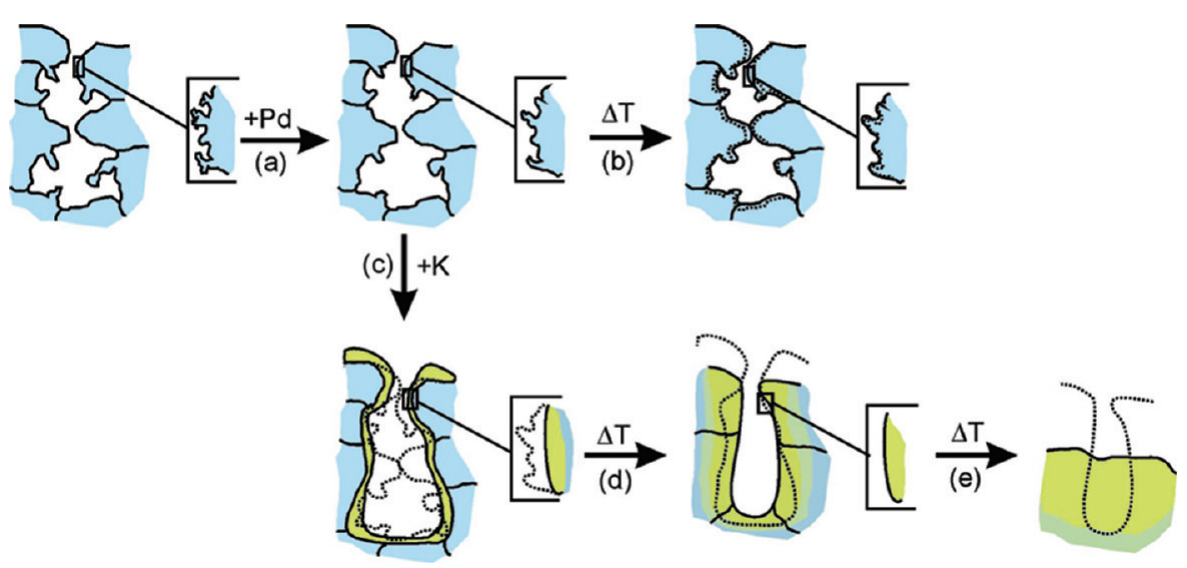

Figure 10. Schematic representation of the entire process starting from deposition of palladium onto SA support to further doping and thermal treatments. The light green represents the support interacted with potassium carbonate; conversely, the light blue indicates the material that remains unchanged.

performance cannot be performed apart from considering that Pd crystallites are not deposited on an inert and unmodifiable surface.

Among the investigated supports, viz., activated carbons, $\gamma-\mathrm{Al}_{2} \mathrm{O}_{3}, \mathrm{SiO}_{2}$, and $\mathrm{SiO}_{2}-\mathrm{Al}_{2} \mathrm{O}_{3}$ (SA), the SA one is extremely plastic and reactive, so it has been considered for additional investigations. We have demonstrated that many processes, summarized in Figure 10, contribute to modify the support morphology at nano- and microscale level.

During the Pd deposition (Figure 10a), the support itself is partially dissolved and removed as a result of both contact with the basic precipitating agent and the final washing. The dissolution acts mainly on irregularities and diaphragms, resulting in a decrease of $A_{\mathrm{s}}$ and an increase in the pore size, partly true (demolition of diaphragms) and partly apparent (disappearance of the narrow interstices between the irregularities).

When the undoped sample is treated at high temperature (Figure 10b), only modest phenomena are observed. The loss of $\mathrm{H}_{2} \mathrm{O}$ (in particular between 393 and $673 \mathrm{~K}$ ) causes the occlusion of some narrow channels connecting contiguous pores, and/or a weak shrinking and smoothing of pores. Consequently, a weak decline of $A_{\mathrm{s}}$ and $V_{\mathrm{p}}$ at constant $D_{\mathrm{m}}$ is observed.

During the doping with potassium carbonate (Figure 10c), the support dissolution continues (the greater the carbonate concentration, the greater the dissolution extent). In this case, the dissolved material is not removed, but reprecipitates, at least partially, as potassium salt during the subsequent drying at $393 \mathrm{~K}$. This involves the definitive disappearance of irregularities and, probably, also the removal of some pore walls. The reprecipitation of support, as well as that of unreacted carbonate, occurs mainly outside the pores. As a result, there is an enlargement of pores and a decrease of $A_{\mathrm{s}}$.

When doped samples are treated at high temperature (Figure $10 \mathrm{~d}, \mathrm{e}$ ), the reaction between carbonate and support (with release of $\mathrm{CO}_{2}$ ) causes the mobilization of the support itself ("alkaline fusion"), with sintering phenomena that can reach the total collapse of the porous structure at a temperature that becomes lower as the concentration of potassium carbonate becomes greater.

The investigated support is a good (and quite complete) model of the processes that can occur on material used as a support for noble metal catalysts. One or more of the observed processes, namely, dissolution and removal or reprecipitation of support during catalyst preparation and doping, change of composition, transfer of material from the inner pores to outer particles, change of local morphology with smoothing or destruction of pore walls, shrinking, sintering of support elementary particles, can be observed on most of the supports.

The modification of the support influences, directly or indirectly, Pd crystallites, that can be doped or even covered by materials from support, made more or less accessible or even inaccessible by pore narrowing, widening or blocking, as demonstrated by TEM, CO chemisorption, and FTIR spectroscopy of adsorbed CO. As a result, most properties of Pd crystallites, such as sensitivity to sintering, chemical composition, and availability, depend on support modification during catalyst manufacture.

Acknowledgment. We thank Massimo Graziani (Chimet S.p. A) for the $\mathrm{N}_{2}$ adsorption and $\mathrm{CO}$ chemisorption measurements. The stimulating discussion with L. Bertinetti and A. Zecchina is gratefully acknowledged. 